\title{
Integrated Reporting: Insights, gaps and an agenda for future research
}

\author{
Charl de Villiers \\ Waikato Management School, The University of Waikato, Hamilton, \\ New Zealand and The University of Pretoria, Pretoria, South Africa, and \\ Leonardo Rinaldi and Jeffrey Unerman \\ School of Management, Royal Holloway University of London, Egham, UK
}

\begin{abstract}
Purpose - The purpose of this paper is to synthesise insights from accounting and accountability research into the rapidly emerging field of integrated reporting and proposes a comprehensive agenda for future research in this area. In so doing, it draws upon insights from other papers in this special issue of Accounting, Auditing and Accountability Journal on the theme of integrated reporting.

Design/methodology/approach - The paper draws upon and synthesises academic analysis and insights provided in the embryonic integrated reporting academic literature in conjunction with policy pronouncements.

Findings - The paper shows that the rapid development of integrated reporting policy, and early developments of practice, present theoretical and empirical challenges because of the different ways in which integrated reporting is understood and enacted within institutions. It highlights many areas where further robust academic research is needed to guide developments in policy and practice.

Research limitations/implications - The paper provide academics, regulators and reporting organisations with insights into issues and aspects of integrated reporting that need further development and need robust evidence to help inform improvements in policy and practice. A key limitation is that it draws upon a synthesis of the existing literature which is at quite an early stage of development - but provides scope for considerable further development.

Originality/value - The paper provides the growing number of academic researchers in this emerging area with a foundation and agenda upon which they can build their research.
\end{abstract}

Keywords Sustainability reporting, Integrated reporting, IIRC

Paper type Research paper

\section{Introduction}

Social and environmental reporting has a long history (Hogner, 1982; Guthrie and Parker, 1989; Buhr, 2007). Initially this reporting took place predominantly through disclosures within corporate annual (financial) reports. Over the past two decades, however, social and environmental disclosures have increasingly been made in separate stand-alone reports in addition to a variety of other media such as web sites (Cho et al., 2009). These stand-alone social and environmental reports have become more complex (and long) as a greater range of issues has been disclosed to meet the supposed information needs of a range of stakeholders. More recently, possibly in

The authors are very grateful to the authors and the referees who contributed to this special issue, helping raise important and robust insights into developing integrated reporting practices. The authors are also very grateful to James Guthrie, who encouraged the special issue and dealt with this paper editorially, as well as the two referees of this paper for their valuable insights and comments. Any remaining errors are, however, a result of our own work. 
response to the increased complexity and length of stand-alone reports, there have been moves to recombine some social and environmental disclosures with financial disclosures in single reports. In contrast to earlier social and environmental disclosures made within annual reports, where the social and environmental information was not integrated with the financial information, these recent moves have sought to integrate social, environmental, financial and governance information (Dey and Burns, 2010; Hopwood et al., 2010). The resulting practices have come to be known as integrated reporting.

Integrated reporting has rapidly gained considerable prominence since the formation in 2010 of the International Integrated Reporting Committee (IIRC - subsequently renamed the International Integrated Reporting Council). Although the IIRC has become the dominant body globally in developing policy and practice around integrated reporting, it was not the first mover in this area. Some innovative reporting organisations had individually pioneered such practices, and in South Africa, where integrated reporting is a listing requirement, guidelines for integrated reporting were being developed before the formation of the IIRC (Cheng et al., 2014).

Although integrated reporting is a relatively new area of policy and practice, both public policy and organisational practices in this area have developed rapidly. Integrated reporting has also attracted a great deal of academic attention, and a body of literature is beginning to develop. As a rapidly developing accounting regulatory arena, studying integrated reporting provides an opportunity to study many aspects of the development of accounting regulation over a much shorter period than has typically been the case for financial accounting standards. It may therefore be possible for individual studies focusing on integrated reporting to provide a richer and more holistic picture of the development of reporting regulations than when studying financial accounting standard setting. As academic interest in integrated reporting continues to grow, academic documentation of initial developments in integrated reporting - along with a range of insights into aspects of integrated reporting - can provide academics researching in this area with a solid foundation upon which to build their research. It can also provide regulators and reporting organisations with valuable insights to help inform further development of policy and practice.

The aim of this paper is to begin to meet this need by tracing the early development and current state-of-play of integrated reporting and setting out a comprehensive agenda for future research. In addressing this aim the paper draws upon academic analysis and insights provided in the embryonic integrated reporting academic literature, including within other papers in this special issue of Accounting, Auditing and Accountability Journal on the theme of integrated reporting.

The next section of the paper explains several of the key developments in social and environmental reporting that appear to have (at least partly) prompted moves towards integrated reporting. Section 3 outlines pioneering work in integrated reporting by the Danish pharmaceutical company Novo Nordisk and the South African King Commission on Corporate Governance, before aspects of the IIRC's integrated reporting framework are discussed in Section 4. Section 5 continues with a discussion of developments in selected countries. Section 6 outlines the findings of several research studies into aspects of integrated reporting, including those in this $A A A J$ special issue. Section 7 sets out a comprehensive agenda for future research into integrated reporting, incorporating a series of potential research questions that need addressing to help provide a robust and critical evidence base to guide the further development of policy and practice. The final section draws conclusions. 


\section{Antecedents of integrating reporting}

The last 20 years have seen considerable development in academic literature on accounting and accountability systems for the combined management and reporting of financial and non-financial performance. Academics and practitioners have analysed the interaction between managements' strategic propositions, organisational control systems and performance measurement and reporting systems (Parker, 2012). Among several proposals advanced by scholars within the accounting, management and governance domains (Nixon and Burns, 2012; Giovannoni and Maraghini, 2013), four frameworks that have emerged are: the Balanced Scorecard, the Triple Bottom Line, Sustainability Reporting and Integrated Reporting.

The Balanced Scorecard is an internal performance measurement, reporting and management control mechanism that integrates financial and non-financial strategic measures (Kaplan and Norton, 1996). In doing so it aims not only to overcome the limits often associated with financial indicators (that these measures account for past performance while non-financial measures have the potential to drive future performance) (Nørreklit, 2003) but it also aligns individual/departmental goals with the overall strategic aims of the organisation through tangible outcomes and measures.

Each organisation chooses measures its managers consider appropriate to include in the Balanced Scorecard. These are measures that focus management attention on the most important strategic and operational aspects of the organisation. Even though many Balanced Scorecard measures are non-financial and forward looking, these measures do not necessarily include social, environmental and sustainability issues, and it is unlikely that Balanced Scorecard measures will provide any form of integration between these measures. The Balanced Scorecard is more likely to include discreet measures of aspects that warrant management attention.

Turning now to external reporting, the Triple Bottom Line became popular towards the end of 1990s (Elkington, 2004). It provided a new language to express the sustainability concept to an audience more accustomed to external disclosure of the economic bottom line (Adams et al., 2004). The Triple Bottom Line suggested the need to also disclose information regarding environmental and social matters (Elkington, 1998).

More recently, there has been a tendency to refer to social and environmental disclosures as sustainability disclosures. The meaning of the term sustainability is contested and critics claim that the term "sustainability disclosure" itself has little to do with sustainability and is much more about an attempt by business to connect with the concept of sustainability in a symbolic way, whilst continuing with business as usual (Milne et al., 2009; Buhr et al., 2014). The Triple Bottom Line has been similarly criticised (Brown et al., 2009).

While drawing on multiple strands, the early development of integrated reporting policies and practices appears to have largely been informed and driven by considerations linked to social and environmental reporting.

Until the latter part of the twentieth century much social and environmental reporting took place via the medium of corporate annual reports. Although these reports were predominantly financial in orientation, some organisations used parts of their annual reports to disclose selected information about their social and environmental impacts and their policies towards managing the interactions between the organisation, the society in which it operated, and the natural environment (Unerman, 2000). Research indicates that these social and environmental disclosures within annual reports appear to have been largely motivated by organisational or managerial desires to meet the 
perceived information requirements of the stakeholders who held the most economic power in relation to a reporting organisation (Neu et al., 1998; Deegan, 2002).

As social and environmental reporting became more widely practiced, and as the amount of social and environmental information reported by many organisations expanded, increasingly organisations began to separate out social and environmental disclosures, using media other than the annual report to disclose much of this information. For many of these organisations, the annual report became primarily focused on communicating information of core relevance to their financial stakeholders (de Villiers and van Staden, 2011). Information considered to be primarily of relevance to other stakeholders was published (often in increasing volume and complexity) in stand-alone social and environmental reports and/or other interactive media (such as sustainability web sites) (de Villiers and van Staden, 2011).

In tandem with the growth in stand-alone social and environmental reporting practices, initiatives to develop voluntary reporting standards to guide organisations in initiating and implementing these reporting practices developed. The Institute of Social and Ethical Accountability (commonly known as AccountAbility) and the Global Reporting Initiative (commonly known by the acronym GRI) were among the membership organisations that developed the most enduring and widely adopted reporting and assurance standards for social and environmental reporting (Buhr et al., 2014). As is the case with financial reporting standards, one of the aims of such standardisation in social and environmental reporting was to enhance the credibility and comparability of reports that have been compiled in compliance with the standards.

In practice, however, as the GRI guidelines became more complex and covered a broader range of social, environmental and governance issues, sustainability reports compiled in accordance with the GRI standards also became more complex and lengthy. Although such reports might have contained a wealth of information about a reporting organisation's social, environmental and economic impacts, practices and policies, because of the level of detail in the report it was often difficult for readers of a GRI compliant report to systematically link information across different policies, practices and impacts. Such linking is considered important because actions or impacts in one area will often lead to other impacts in other areas (Hopwood et al., 2010). The more information there is in a report about individual social, environmental and economic impacts, policies and practices, the greater is the likelihood of information overload for readers of the report (Fries et al., 2010). With greater information overload, the more difficult it is for all but the most determined and informed readers of a sustainability report to appreciate the linkages between different social, environmental and economic impacts.

In 2004, the Prince's Accounting for Sustainability Project was formed. One of its aims was to address this disconnect for many readers of sustainability reports. Over the following years it developed guidance for what it referred to as "connected reporting" where organisations were expected to draw report readers' attention to the main connections between those social, environmental and economic actions and outcomes that were material for the reporting organisation (Hopwood et al., 2010).

In the following years, several reporting organisations and regulatory bodies responded to the challenge of providing a more holistic picture within sustainability reports of interacting material social, environmental and economic actions and impacts. Among the pioneering reporting organisations innovating in the area of integrated (rather than connected) reporting was the Danish pharmaceutical company Novo Nordisk. The first regulatory initiative on integrated reporting was in 
South Africa, as discussed further below. In 2010, the GRI and the Prince's Accounting for Sustainability Project jointly formed the IIRC to develop integrated reporting at a global level.

At the outset, one of the main distinguishing features of integrated reporting was its aim to provide a concise report (in a relatively few pages) that would indicate an organisation's most material social, environmental and economic actions, outcomes, risks and opportunities in a manner that reflected the integrated nature of these factors for the organisation (IIRC, 2012). The intention was to use electronic forms of reporting to allow users of integrated reports to drill down to more detailed reports and other information on those elements reported in the integrated report in which they were most interested.

Subsequent developments in the IIRC's thinking on integrated reporting shifted the emphasis from an organisation's integrated report being a high level overview, towards the integrated report replacing other forms of corporate reporting:

The main output of Integrated Reporting is an Integrated Report: a single report that the IIRC anticipates will become an organization's primary report, replacing rather than adding to existing requirements [...] [bringing] together the different strands of reporting into a coherent, integrated whole (IIRC, 2011, pp. 6-7 emphasis added).

However, this ambition posed a substantive challenge to the guiding principle of providing a concise integrated picture of an organisation's main actions, impacts, risks and opportunities. The IIRC's definition of integrated reports subsequently developed to:

An integrated report is a concise communication about how an organization's strategy, governance, performance and prospects, in the context of its external environment, lead to the creation of value over the short, medium and long term. [...] an integrated report may be prepared in response to existing compliance requirements $[\ldots]$ If the report is required to include specified information beyond that required by this Framework, the report can still be considered an integrated report (IIRC, 2013d, pp. 7-8).

The IIRC therefore appear to have recognised that existing corporate reporting rules require fuller and more comprehensive financial disclosure requirements than would be possible if a relatively short integrated report were to replace (and broaden) existing financial reporting requirements.

Having explained some of the main antecedents of integrated reporting, the next section of this paper outlines two pioneering policy and practitioner initiatives on integrated reporting.

\section{Pioneers of integrated reporting}

In this section we briefly explain the pioneering work in two integrated reporting initiatives - those of Novo Nordisk and the South African King Commission.

Novo Nordisk's approach to integrated reporting appears to have been driven by an aspiration to develop a culture of integration in measurement and management. In working towards this aspiration, Novo Nordisk has been a leader in expanding and developing voluntary non-financial disclosures. From 2003, the company became a leader in the quest to measure and report social, environmental and financial performance within a single document. Driven by the belief that their integrated disclosure was not just the end of an innovative reporting process, but the beginning of a new way of management that encompasses corporate governance, employee culture, emergent and inventive management tools and rigorous performance measurement. 
Novo Nordisk acted as a pioneer of the notion of integrated thinking and embedding of sustainability within business strategy - known as the Novo Nordisk Way of Management (Dey and Burns, 2010).

The 2013 Annual Report celebrated Novo Nordisk's first decade of integrated reporting and provided a consolidated account of financial, social and environmental performance. The combined statements were structured to increase the focus on what managers believe were the most significant factors that drove the company's performance in accordance with a triple bottom line perspective, with the intention of increasing transparency (Novo Nordisk, 2013). However, apart from the institution of an integrated structure, Dey and Burns (2010) highlight a belief that managing values and principles around sustainability is as important as more tangible outcomes, with this being a precondition to embedding sustainability within an organisation like Novo Nordisk.

At a country rather than organisation level, in South Africa business organisations were increasingly called to account for their non-financial performance. During the negotiations from 1990 to 1994 to establish a new order following apartheid, key elements of the extant economic and social order were questioned, including the right of companies to operate and make a profit (de Villiers and van Staden, 2006). This questioning social milieu, under conditions of entrenched social and economic inequalities, provided the backdrop for the King reports on corporate governance, issued by the Institute of Directors in South Africa in 1994 (King I), 2002 (King II) and 2009 (King III)[1]. This social setting may explain why the King reports emphasise social and environmental governance to a greater extent than similar reports and guidelines elsewhere in the world, at that time.

Following King III, where the idea of integrated reporting was expounded, South Africa's Integrated Reporting Committee initiated a discussion on accountability for the impact of business activities (ACCA, 2012). The motive behind the promotion of integrated reporting in South Africa was a belief that the existing incremental disclosure changes were not sufficient, and for this reason a fundamental shift in the way companies and directors acted and organised themselves was needed (IoDSA and King III, 2009). These changes had important repercussions both on the performance of businesses and on the types of information that stakeholders needed to assess this performance (IIRC, 2011, 2013d).

King III urged organisations to commit to the principles of integrated thinking; promoting the concept that strategy, governance and sustainability are intimately entwined. It also suggested that organisations should integrate their reporting approaches and practices on risks and opportunities through financial and sustainability considerations. The King III principles were subsequently integrated into listing requirements of the Johannesburg Securities Exchange, requiring listed companies to combine financial performance information with sustainability performance information within their annual reports and issue an integrated report, or disclose why they had not done so. Although "comply or explain" approaches to disclosure in financial reporting are not new, the novelty of South African integrated reporting requirements was the integration of social, environmental and economic issues in a manner that acknowledges the interdependency of the natural environment, socio-political and global economic sub-systems. As a result, to enable stakeholders to make a more informed assessment of the economic value of a company it was recommended that financial, environmental, social and governance reports were produced and made available in an integrated fashion, rather than being developed separately (IoDSA and King III, 2009). The idea is 
that the integrated report acts as a high level explanation of the main issues with the detail provided in separate but linked reports. Integrated reporting guidance for South African companies was subsequently developed by South Africa's Integrated Reporting Committee, and will be discussed in the next section along with, and in contrast to, the work of the IIRC.

\section{Regulatory developments around integrated reporting}

In contrast to the national focus of South Africa's Integrated Reporting Committee, the IIRC was established with a global remit. The IIRC has developed as a quasi-regulatory body attempting to ensure a broad universal adoption of integrated reporting though the creation of a globally accepted integrated reporting framework. The IIRC's integrated reporting framework aims to bring together financial, environmental, social and governance information in a clear, concise, consistent and comparable format (IIRC, 2013b, c, d).

A recently signed memorandum of understanding between the IIRC and the Sustainability Accounting Standards Board emphasises that tearing down internal barriers and lessening duplication can bring greater cohesion and efficiency to the accounting and reporting process. This, according to these two international bodies, can help stakeholders elicit from organisations material information about their strategy, governance, performance and prospects in a clear, concise and comparable format (IIRC and SASB, 2013). An essential element of this approach to integrated reporting is providing stakeholders with additional information to help them make more informed assessments of companies and their long-term prospects (EY, 2013b).

The IIRC's mission is to change the condition where financial and non-financial information are accounted for in isolation from each other towards integrated thinking which is embedded within mainstream management and accounting practice enabling integrated reporting to become the corporate reporting norm (IIRC, 2013c, p. iv; IIRC, 2013d, p. 2). For the IIRC, the main purpose of integrated reporting is to provide a broader and more connected account of organisational performance than is provided by traditional financial and/or sustainability reporting.

According to the IIRC (2013c, d), integrated reporting promotes the access, use and the degree of dependency of the reporting organisation on a variety of social, environmental and economic resources; its relation with capital (understood as consisting of financial, manufactured, intellectual, human, social and relationship, and natural capitals, i.e. including externalities); and the organisation's impact upon these different forms of capital.

Although the IIRC's vision of integrated reporting shares some characteristics with the widely-used GRI sustainability reporting framework and with developments of integrated reporting in South Africa, there are also substantive differences. In the next paragraphs we will highlight one of the main differences, namely the IIRC's increasing focus on the interests and related information needs of providers of financial capital as against the South African Integrated Reporting Committee's initial[2] broader perspective and the GRI's continued broader perspective that encompass the interests of a wider range of stakeholders.

According to the GRI, "the underlying question of sustainability reporting is how an organisation contributes, or aims to contribute in the future, to the improvement or deterioration of economic, environmental and social conditions, developments, and trends at the local, regional or global level" (GRI, 2013, p. 17). Accordingly, GRI-compliant sustainability reports should seek to present performance in relation to 
broader concepts of sustainability. The GRI reporting framework draws on an holistic understanding of sustainable development that requires organisations to demonstrate how they create, use, and preserve a broad array of financial and non-financial resources to meet a wide range of stakeholders' needs. The GRI argues that disclosing corporate performance in isolation from the "context of the limits and demands placed on environmental or social resources" (GRI, 2013, p. 17) would fail to fulfil this underlying aim.

In South Africa, King III also encompasses broader notions of sustainability. It requires that "the leadership of a company embraces the notion of integrated sustainability performance and reporting" (IoDSA and King III, 2009, p. 11). Organisational managers will have to not only report on social, environmental and economic issues, but will also have to factor into their decisions considerations of the possible impact of their actions on the ability of future generations to meet their own needs. The King III ethical approach is grounded in the sustainability considerations rooted in the South African Constitution that imposes responsibilities upon individuals and juristic persons, including business organisations, for the realisation of fundamental rights. This means that business organisations should be responsible citizens and they could be held accountable (IoDSA and King III, 2009).

In 2010, the IIRC's vision of integrated reporting also encompassed a reasonably broad understanding of sustainable development and of the range of stakeholders who might be affected by organisational actions. However now, in contrast to the more stakeholder-inclusive underpinnings of the GRI and of the early South African development of integrated reporting, a rather different interpretation of corporate sustainability has become embedded at the heart of the IIRC integrated reporting framework.

In 2013 the IIRC explained integrated reporting as "promoting a more cohesive and efficient approach to corporate reporting that draws on different reporting strands and communicates the full range of factors that materially affect the ability of an organisation to create value over time" (IIRC, 2013d, p. 3). According to the IIRC, this should contribute to allowing efficient and productive capital allocation and act as a force for financial stability and sustainability. Thus, the IIRC now is promoting the sustainability of the creation of (mainly financial) value over the short, medium and long term. The IIRC emphasises that "a sustainable planet and a stable economy require sustainable businesses that support broader societal interests by undertaking long term, as well as short and medium term, value creation within planetary limits and societal expectations" (IIRC, 2013a, p. 6). This meaning of sustainability is linked to the efficient use of non-financial resources aimed at, and instrumental to, the perpetuation of economic value creation. In the 2013 IIRC's framework, organisations should employ, and account for, a governance structure to support this function of economic value creation.

The dominance of "economic value" creation can be problematic. For example, the Capitals Background Paper for the IIRC's Integrated Reporting framework mentions trade-offs between capitals, "e.g. creating employment, which increases human capital, through an activity that negatively affects the environment and therefore decreases natural capital" (ACCA and NBA, 2013, p. 22). In this way, the increase of economic capital at the expense of damage to natural capital could be regarded as being implicitly condoned. This is reminiscent of practices underlying long-standing critiques in the academic literature of some business-case reasoning for sustainability, where pro-sustainable development actions can only be supported if they also deliver 
economic gains. Where there is a conflict between economic and social/environmental outcomes the economic tends to take precedence (Crane et al., 2014).

If integrated reporting is intended to discharge duties of accountability for responsibilities most closely connected to the notion of financial value creation, its potential to help stakeholders' develop an understanding of social and environmental impacts and hold managers accountable for them is constrained. Despite, or perhaps because of, the IIRC's recent focus on the interests and information needs of providers of financial capital, its vision of has developed considerable traction among policy-makers and practitioners. Several developments in these areas are explained in the next section.

\section{Recent developments in integrated reporting policies and practices}

In this section, illustrations of recent developments in integrated reporting practice in a selection of countries will be used to demonstrate some of the ways in which integrated reporting, especially under the auspices of the IIRC, is gaining traction. The IIRC only published its first complete framework for integrated reporting in late 2013, so at the time of writing this paper it is too early for many organisations to have published IIRC compliant integrated reports. However, there are over 100 organisations that are part of the IIRC pilot programme for reporters. This pilot programme's aim is to provide members of the programme with: "the opportunity to discuss and challenge developing technical material, test its application and share learning and experiences" (IIRC, 2014b). These organisations are working on developing and sharing "best practice" in compiling integrated reports drawn up under the IIRC's framework. Although many of these organisations, have not yet published such an integrated report, several will have prototype reports (or elements of such reports) that are not yet considered ready for external publication. There is also a pilot programme investor network, focusing on "providing constructive feedback on emerging reporting from the Pilot Programme Business Network" (IIRC, 2014b). The focus of this "users of integrated reporting pilot network" is investors, reinforcing the development of the IIRC's version of integrated reporting to meet the needs of providers of financial capital.

While evidence from individual reporting organisations on the development of integrated reporting is not yet widely available, there is evidence showing movements in some countries towards integrated reporting. We will start our brief coverage of several of these developments with South Africa, the pioneering nation for integrated reporting. We will then move on to explain some key developments in other countries (e.g. the UK, the Netherland, Spain, Australia, Singapore, Japan and the USA).

South Africa was a pioneer in the development and mandating of integrated reporting. Companies listed on the Johannesburg Stock Exchange are required to adopt integrated reporting, using the South African integrated reporting framework for its preparation. This framework had a greater focus on broader social, environmental and sustainability issues than the IIRC Framework. Listed companies are required to issue an integrated report or explain why they have not published such a report. So far most companies have chosen to issue an integrated report. Although, as noted in the last section, the South African integrated reporting framework was more stakeholderinclusive, the Integrated Reporting Committee of South Africa recently (12 March 2014) endorsed the IIRC's investor value creation focused Integrated Reporting Framework (PWC, 2013f; IIRC, 2014a).

Unlike South Africa, integrated reporting practices are not mandatory in any other country. However, they have attracted varying levels of rhetorical support from 
regulators in some countries and regions. These practices also build upon sustainability reporting practices that are more widely developed and adopted in some countries than others.

The UK is regarded as one of the global leaders in corporate reporting (KPMG, 2013). Also PWC (2013a) reviewed the challenges posed by the demands of integration between strategic focus, accountability and reporting in light of recent developments in regulatory changes (such as the release of the GRI G4 Sustainability Guidelines, and the IIRC Integrated Reporting framework) by way of a review of annual reports issued by the FTSE 100 companies. Most of the surveyed companies were starting to address some of the fundamental issues of integrated reporting, but this was at broad level. For example, 99 per cent explained their strategic aims, priorities and progress, although only 40 per cent provided detailed explanations of the actions taken to deliver on these strategies. However, a much lower proportion reported on their social and environmental impacts, for example 31 per cent discussed the future availability of the material natural, social, human or manufactured resources required to create value (PWC, 2013a). However, what was missing was an understanding of the interrelationships between all the critical elements of reporting. For example, the level of detail provided in defining the business model and its integration with other reporting areas, such as sustainability, risks and strategy was limited (PWC, 2013a). The Institute of Chartered Accountant of England and Wales described integrated reporting as having "the potential to act as a catalyst for major improvements in business reporting" (ICAEW, 2013) adding that in the UK many organisations are already incorporating the principles of integrated reporting into their existing reporting.

In the Netherlands, although many companies participated in PWC's (2013c) survey of annual reports issued by the top 50 companies, it was found that the quality of their integrated disclosures was low. The areas that were identified as the most critical and subject to improvement were the communication of: the main risks and opportunities; the ways in which resources are allocated to achieve strategic goals; and the definition and measurement of performance (PWC, 2013c). Within the first area, only 3 per cent of the top 50 companies were found to include in their integrated reporting information about the impact and probability of the identified risks, thus providing little insight into the dynamics of their risk profiles. Second, while companies acknowledged the significance of reporting on their strategy (90 per cent of the surveyed organisations included some statements relating to their overall strategic ambition and 54 per cent provided discussions about how these strategic priorities were aligned to overall goals) their disclosure was still not entirely clear about how resources were going to be allocated to achieve the stated strategic plans. Finally, within the latter area, PWC found that the definition and measurement of companies' non-financial value creation represented a serious concern for investors in the top 50 companies. PWC (2013c) found that the Dutch top 50 companies tend to avoid reporting on their economic, environmental and social impact and other important performance indicators, such as customer satisfaction. The then focus remains on historical data with companies "shying away from broaching the topic of what the future may hold for them" (PWC, 2013c, p. 9).

PWC has also reviewed the key attributes of integrated reporting among Spanish IBEX 35 companies (PWC, 2013e). Examining "content", "quality" and "level of integration", the survey described that, compared to previous years of investigation (PWC, 2012) Spanish companies were improving the integration of economic, social 
and environmental information. In terms of content, for example, 80 per cent of IBEX 35 companies provided some degree of information about the growth prospects of the markets in which they operated. In the field of corporate risks, the quality of information improved and 100 per cent of the IBEX 35 reported on key business risks. Similarly in the field of business model, where 94 per cent of organisations made reference to the key capabilities and the key resources they depended upon to create and maintain competitive advantage (even though only 10 per cent provided detail about how they managed and controlled them). Finally, in terms of level of integration, the survey showed that only 11 per cent of IBEX 35 companies integrated strategy and sustainability. Another analysis, entitled "Integrated Reporting in IBEX 35 entities", assessed the IBEX 35 companies against a similar study regarding UK FTSE 250 and FTSE 100 reporting practices. This analysis showed that the integrated reporting practices of Spanish- and UK-listed companies were broadly similar (PWC, 2013g, 2014).

In Australia, ACCA and Net Balance Foundation assessed the public reporting of companies within the ASX 50 to identify the extent to which these organisations had moved towards integration (ACCA, 2011). The assessment was guided by six key criteria that addressed the aspects of operations that would be affected should an organisation adopt an integration agenda (namely: mission and strategy, management approach, performance tracking, risk management, stakeholder engagement and the format of public reporting). This research found that some of the ASX 50 companies had made progress towards the integration of material non-financial concerns into their strategy, management processes and public reporting, also demonstrating a relatively transparent and comprehensive approach to stakeholder management. A variety of reporting formats (including, for instance, corporate social responsibility reports and annual reports) across a range of communication platforms (e.g. web sites and newsletters) were used to meet the various information needs of stakeholders. However, the majority of ASX 50 companies did not disclose non-financial risks or systematically assess the financial implications of these risks. The research also identified that interest in non-financial matters among investors (except climate change risk) was low in Australia and that broader considerations of impacts and time frames would be required. However, in terms of environmental disclosure, Australian individual investors required extensive corporate disclosure, many even voicing the need for mandating disclosures (de Villiers and van Staden, 2010).

The Singapore Accountancy Commission (SAC) recently publicly endorsed the Integrated Reporting Framework arguing that its adoption would provide a more comprehensive and cohesive picture of firms that would then contribute to greater information transparency. The greater information transparency and balanced interests among stakeholders brought about by the integration of financial and sustainability dimensions were envisaged to be beneficial to stakeholders. More specifically, SAC linked the adoption of integrated reporting to increasing the attractiveness of Singapore's business environment, where overseas investors (institutional investors in particular) could be assured of protection through progressive disclosure rules (ASRC and SAC, 2013). The SAC is currently undertaking several research projects "with a goal to promoting integrated reporting in Singapore and the Southeast Asian region" (ASRC and SAC, 2013). These will include: an educational document to raise awareness of stakeholders and firms about the benefits of integrated reporting; practice guides aimed to provide guidance for firms keen to adopt integrated reporting; issues such as integrated reporting assurance; and integration between the annual report and 
integrated report. At the end of 2014, the SAC intends to produce its own Annual Report based on the principles laid out in the integrated reporting framework.

Japan has developed a distinctive set of corporate governance and accounting practices over the years, engendered by the specific interplay of material, cultural and environmental factors (Yamagami and Kokubu, 1991). Yonekura et al. (2012) explain that the Japanese model of corporate governance reflects the Japanese notion of the community firm with an emphasis on stakeholders rather than shareholders as the primary beneficiaries of corporate activity. Consequently, stakeholders and particularly employees are seen as exercising substantive control in this Japanese model, while the purpose of the company is understood as being to increase long-term market share, reflecting an emphasis on employees (Yonekura et al., 2012). This was particularly prominent after the Great East Japan Earthquake 2011, which raised the pressure on companies to conduct social and environmental activities aimed at bringing the affected communities back to normality (Mizobata et al., 2014).

In July 2012, the Ministry of the Economy, Trade and Industry established a Corporate Reporting Laboratory aimed at reasserting a focus on long-term investment and unlocking corporate value, though an enhanced dialogue between organisations and investors. The laboratory is developing several research projects and initiatives, including a Task Force on IR/Corporate Value, a Working Group on Corporate Governance Dialogue and a Task Force on Corporate Awareness of Corporate Governance (The Ministry of Economy Trade and Industry of Japan, 2013). Corporate reporting reform towards Integrated Reporting is also obtaining support from the "Expert Committee on Desirable Market Economy System", that was established under the Council on Economic and Fiscal Policy of Japan. The Committee "has held discussions in order to study the shape of a market economy system under which sustainable growth can be achieved not by resorting to short-term speculation but by prioritising medium- and long-term investments and to disseminate it to the world" (Expert Committee on Desirable Market Economy System, 2013, p. 1). According to the Expert committee report:

Through integrated reporting, diversified information necessary for analyzing and evaluating companies is disclosed in a concise way. Such information includes a company's environmental activities and relationship with local communities, as well as its management strategy and medium-and long-term forecast, etc. in addition to financial information. Integrated reporting is thus effective in describing the entirety of the company's activities. If investors and other stakeholders come to fully understand the overall value to be created by the company as a result of its efforts for integrated reporting, etc. this will help the company's medium-and long-term growth (Expert Committee on Desirable Market Economy System, 2013, p. 17).

A survey conducted in 2013 by the Japan Investor Relations Association highlighted that a number of Japanese companies have either already created an integrated report or are planning to produce such a report (JSIF, 2013).

Integrated reporting is also developing within other countries such as Germany (PWC, 2013b), France (Institut RSE Management, 2012; République Française, 2012) and Brazil (IIRC, 2013c), whereas there are a number of important economies that have not embraced it to the same extent.

For example, in the USA sustainability reporting has been a much less widely developed practice than in Europe, South Africa or Australasia. However, the US Environmental Protection Agency commissioned a report to determine value drivers in companies related to natural, social and intellectual capital in addition to more traditional financial forms of capital, and to present this information to investors (IEC, 2008). 
The aim was to enable stakeholders to access information around social and environmental externalities. These included negative externalities, such as pollution, natural resource depletion and human rights abuses, as well as positive externalities such as job creation, community development and cures for diseases (IRRC, 2013). Beginning in the 1970s, the US Securities and Exchange Commission (SEC) started establishing regulations for disclosing environmental liabilities and contingencies as well as material impacts of environmental laws and regulations (IEC, 2008). More recently, the SEC addressed climate change, board diversity, mine safety, conflict minerals, payments to governments by resource extraction firms and other sustainability topics in disclosure rulemaking and guidance to companies (SEC, 2008). Due to concerns around potential litigation, companies in the USA have traditionally been reluctant to disclose future related information, one of the corner stones of integrated reporting. It will be interesting to see how US companies deal with this issue as integrated reporting develops and becomes more widespread.

At a more cross-national level, integrated reporting is increasingly receiving support from a series of market intermediaries including the main international accounting firms (e.g. Deloitte and Touche, 2011; EY, 2013a; KPMG, 2013; PWC, 2013d), national and international professional organisations (e.g. ACCA, 2012; Frost et al., 2012; CIMA et al., 2013; ICAEW, 2013) and international regulatory bodies such as the Sustainability Accounting Standards Board and International Accounting Standards Board (e.g. IIRC and IFRS, 2013; IIRC and SASB, 2013).

These insights show recent developments in integrated reporting and provide an indication of the complexity involved in implementing integrated reporting practices at an international level. These examples also highlight that integrated reporting draws on sustainability reporting practices that are more widely developed and adopted in some countries rather than others. Finally, a paucity of knowledge of how integrated reporting links with other accounting issues seem to emerge from the above insights. It is therefore crucial to continue to closely monitor the state of implementation of integrated reporting to develop a deeper understanding, for example, of how the allocation of financial and other capitals relate to the enhancement of social and natural value. In the next section, we discuss some of these issues and research opportunities by building upon the research insights provided by other papers published in this special issue.

\section{Integrated reporting research findings}

Given the developments in integrated reporting, there is a dearth of research papers in this area. However, Dey and Burns (2010) examined the Novo Nordisk pioneering experience with integrated reporting (as discussed earlier in this paper). A few papers have also discussed integrated reporting's connections with other accounting issues, such as an XBRL taxonomy for integrated reporting (Gonzálbez and Rodríguez, 2012), an opportunity for Australian NGOs (Adams and Simnett, 2011), and the accounting curriculum implications of integrated reporting (Owen, 2013). There are several short articles that introduce and/or outline aspects of integrated reporting without contributing substantive new academic insights.

Among the high quality papers that do what we regard to be the core issues and challenges of integrated reporting, Cheng et al. (2014) not only explain the concept of integrated reporting and the IIRC inspired development thereof up to early 2013 but also analyse key issues "as identified and reported to the IIRC by a subcommittee of the International Association for Accounting Education and Research comprised 
of international accounting academics" (p. 90). The three main issues identified by Cheng et al. are a focus on the providers of financial capital, the meaning of and trade-offs between different capitals, and the assurance of integrated reports. These remained contentious, even after the IIRC issued its framework in late 2013. Cheng et al. (2014) also identify several potential integrated reporting research issues.

Our paper now turns to the articles published in this $A A A J$ special issue. Beyond the definitional problems previously discussed, a useful perspective to analyse the impact of integrated reporting practice is to examine its potential to bring about change. Innovation can be stimulated by innovative disclosure practices and/or by shaping the ways in which integrated reporting is conceptualised and enacted.

Within this $A A A J$ special issue, three papers (Brown and Dillard, 2014; Higgins et al., 2014; Stubbs and Higgins, 2014) address the potential of reporting practices employed by early adopters of integrated reporting to foster transitions to more sustainable business practices.

The primary aim of Stubbs and Higgins (2014) is an examination and critique of the extent to which integrated reporting is stimulating innovative disclosure practices. In investigating the internal mechanisms employed by early adopters of integrated reporting in Australia they argue that the approaches and internal mechanisms early adopters use to implement integrated reporting, and whether integrated reporting is driving organisational change, needs to be considered with great attention at this early stage. A key factor in urging this attention is represented by the new challenges driven by integrated reporting compared to sustainability reporting as (according to the definition of integrated reporting), integrated reporting is more closely tied into business strategy and how an organisation creates value.

Stubbs and Higgins (2014) explain that the process of integrated reporting deems finance and strategy teams more prominent in understanding and disclosing non-financial information. They question whether integrated reporting can drive deep transformative change and offer opportunities to reconceptualise the culture of an organisation towards more sustainable outcomes as suggested by Eccles and Krzus (2010).

To shed light on whether integrated reporting is stimulating innovative disclosure mechanisms, Stubbs and Higgins (2014) sought the perspectives of finance managers in addition to sustainability managers. Their main findings indicate that integrated reporting is deemed an incremental phase in sustainability reporting, rather than revolutionary transformation of the existing financial and sustainability reporting approaches. As a result at this stage of implementation of integrated reporting, while the research has provided evidence of changes at the level of resources and structures, there are few signs that in negotiating the integrated story, organisations' core activities and approaches were actually changing.

However, Stubbs and Higgins (2014) do not argue that integrated reporting has not stimulated new innovations in disclosure mechanisms. Rather, despite a lack of fundamental change, the early adopters were found to exhibit a more holistic approach with more engagement between internal stakeholders, such as the financial and the sustainability groups. Also, Stubbs and Higgins (2014) maintain that integrated reporting is in its early adoption stage and it may take more time before innovative disclosure mechanisms emerge. The research also suggests that currently integrated reporting represents a "transition" (Laughlin, 1991) from sustainability reporting rather than a radical innovation driving transformation; and that the lack of comprehensive standards may be inhibiting more widespread adoption. 
This is similar to one of the points made by Higgins et al. (2014), who examine business organisations that were among the first to adopt integrated reporting in Australia. The paper provides an in-depth insight into the processes of institutionalisation of integrated reporting. Through a series of in-depth, semistructured interviews in 15 Australian firms that are amongst the first to experiment with integrated reporting, Higgins et al. (2014) show the importance of "role model" organisations to the institutionalisation of integrated reporting.

Focusing on how organisational actors contribute to the institutionalisation of new activities through language and sensemaking, Higgins et al. (2014) explain the tension created by the simultaneous enactment of two narratives authored by companies' managers. The first narrative regards integrated reporting as an internally crafted story of management's competence to develop strategies capable of meeting the business challenges while protecting investors' interests. The second narrative considers integrated reporting as a disclosure means that conforms to a new global reporting framework. The concurrent enactment of these two narratives, Higgins et al. (2014) argue, has the potential to set up potentially different integrated reports because they involve different materiality judgements and have different implications for the manager's responsibilities.

One consequence Higgins et al. (2014) found to emerge from the managers construction of the institutional order was that, in order to push these tensions to the background and focus on moving forward, managers drew on one or more of three inter-narratives: "time", "strategy" (their company's strategy meets the kinds of external expectations demanded) and "engagement". The time-based inter-narrative draws on discursive strategies to generate coherence to the managers' integrated reporting experience and relies on the natural evolution of time to clear up problems. The strategy-based inter-narrative also draws on discursive strategies, but relies on the communication of the company's strategy as means to relieve the tensions that might be created between telling the company's story and meeting external expectations. Finally, the engagement-based inter-narrative counts on the implementation of material practices, such as the engagement with stakeholders and in committees, to overcome complexity and problems of inconsistency.

Higgins et al. (2014) draw on institutional theory to explain how, in the early stages of integrated reporting, the framing of narratives and inter-narratives by credible organisations can shape how integrated reporting comes to be known and enacted. By showing how the early adopters made sense of integrated reporting, Higgins et al. (2014) suggest that institutionalisation of integrated reporting is unfolding and that isomorphism is likely to follow. However, the institutionalisation of these practices are unlikely to deliver any fundamental change to organisational operations and the expected way to "do" integrated reporting is prone to be influenced by the activities and narratives of the early adopters.

Similar to some of the themes by Stubbs and Higgins (2014) and Higgins et al. (2014), Brown and Dillard (2014) provide a critical discussion of the value of integrated reporting as a change initiative that can contribute to sustainability. In critically assessing integrated reporting, Brown and Dillard (2014) draw on science and technology studies with literature on dialogic and polylogic accountings to conceptually address the controversy between whether and how integrated reporting might advance sustainability goals.

The paper's core is to critically assess integrated reporting so as to "broaden out" and "open up" dialogue and debate about how accounting and reporting standards 
might assist or obstruct efforts to foster sustainable business practices. They argue that "if social and environmental reporting is to empower stakeholders, enhance accountability and foster sustainability transitions, then close attention needs to be paid to political-economic contexts, engagement processes and the design of accounting technologies" (Brown and Dillard, 2014).

Brown and Dillard commences by conceptualising the diverse reactions to the IIRC's proposals in terms of long-standing differences between proponents of business case, stakeholder-accountability and critical approaches to social and environmental reporting. For accountings to open up debate over sustainability issues, Brown and Dillard (2014) suggest the idea of pluralistic accountings as a critical practice aimed at engaging alternative perspectives and developed through civil society-academic networks. In recognising the normative nature of sustainability, Brown and Dillard (2014) criticise the IIRC proposals contending that they offer few critical insights into the current (allegedly unsustainable) ways of thinking, acting and reporting. Therefore, as currently conceived, IIRC proposals may encourage the uptake of weak forms of social and environmental reporting providing a limited and one-sided approach to assessing and reporting on sustainability issues.

Drawing on natural science and technology research, Brown and Dillard (2014) point to ways integrated reporting might be re-articulated. The paper reflects on the enabling possibilities shaping the discussion around three main themes. First they suggest that divergent socio-political perspectives on accounting and engagement could be embraced. The acknowledgement of these perspectives within integrated reporting would provide a basis for genuinely exploring people's commonalities and differences, better so than current monologic approaches. Second, they highlight the importance of recognising the subjective, uncertain and contestable nature of calculations and knowledge so that integrated reporting can explain the relations between accounting technologies and the broader socio-political contexts these relations are embedded in. Third, when divergent socio-political perspectives on accounting and engagement are recognised, then participatory processes and power relations needs to be considered for the production of integrated reports. Brown and Dillard (2014) suggest that accountants could work within interdisciplinary academic groups and civil society groups to co-develop alternative accounts, thus potentially enabling participation by groups who seek to go beyond traditional analysis. The paper introduces a novel framework that enables the evaluation of individual disclosure initiatives (such as the IIRC's integrated reporting) without losing sight of the major sustainability challenges.

Providing a different perspective, van Bommel (2014) examines a multiplicity of views on integrated reporting and shows how legitimacy struggles are resolved in practice around complex accounting technologies in heterogeneous environments. The paper's core is a conceptualisation of the dynamic process through which the practice of integrated reporting attempts to reach a legitimate compromise. Van Bommel (2014) explains that legitimacy concerns are constantly "managed" through re-negotiated compromises. Such is the case in a collective constitutive dialogue over interpretations of what is valued and valuable for integrated reporting.

To shed light upon the multiple logics of valuation at work around integrated reporting, and the difficulties involved in bringing them together in a state of legitimacy, the paper draws on the "sociology of worth" framework (Boltanski and Thévenot, 1999, 2006). This theoretical framing allows van Bommel (2014) to examine and critique how social actors, in moments of uncertainty or dispute, face the need to 
justify and legitimate themselves by making reference to a range of values, principles or models for assessing what is considered as legitimate. The emergence of integrated reporting invokes such a critical moment where controversy arises, and orders of worth (legitimacy) need to be established.

Through 64 in-depth, semi-structured interviews the paper uncovers the legitimacy struggles surrounding the introduction of integrated reporting in the Netherlands, and reinterprets these struggles as conflicts between classes of worth between managers, investors, standards setters, accountants, civil society organisations and NGOs. Also, Van Bommel (2014) explains that orders of worth are potentially always in conflict and legitimacy can only be attained when differences and contestation between orders of worth are reconciled.

The rationales of industrial, market, civic and green orders of worth were found in the case of Dutch developments in integrated reporting. The paper suggests compromise as one possible way to reconcile the differences (the other ways can be found by supporting the dominant order or through private arrangements). Van Bommel (2014) focuses on three mechanisms that contribute to explaining the dynamics of reaching a legitimate compromise: "establishing a common interest", "avoiding clarification" and "maintaining ambiguity and plasticity".

By a detailed critical analysis, van Bommel (2014) observes that the power imbalance between actors/orders of worth is noticeable, suggesting that it might be difficult to position integrated reporting as a durable legitimate compromise as it does not entirely fulfil the mechanisms of reconciliation. Also, all of this offers novel theoretical insight into how the problem of imbalance between legitimacy concerns (namely the dominance of the market/industrial orders of worth) has repercussions also for the perceived ambiguity of integrated reporting.

In the next paper in this $A A A J$ special issue, Haller and van Staden (2014) provide academic insights to the development of integrated reporting by encouraging both academic and institutional discussion on how to apply the concept of integrated reporting into corporate practice. Their paper commences by providing the argument that a structured presentation of the traditional measure of value added in a so-called "value added statement" could be a useful reporting instrument that not only complements but also represents the concept of integrated reporting.

Haller and Van Staden (2014) explain that an integrated report can be regarded as the combination of two strands in corporate reporting that have developed over the last decades. On the one hand, the need to provide information for allowing investors to appraise future corporate economic development, emanating from the corporate world or from actors representing the interests of private capital. On the other hand, there is a willingness to be accountable to a range of stakeholder expectations regarding corporate social and environmental impacts. The independent development of these two strands, it is argued, has led to an increase in disclosures in financial reports and to a growing disclosure of sustainability information.

Against this background Haller and Van Staden (2014) analyse the IIRC's conceptual proposal of integrated reporting to expose whether value added and the value added statement would represent and complement integrated reporting. Through a normative approach based on a comprehensive review of international literature and research, Haller and Van Staden (2014) argue that the measure of value added possesses a "dual" nature in that it incorporates two different aspects. There is the performance aspect (entity focused) and the social aspect (society focused). This duality represents the integration of a company's performance, its efficiency with 
regard to particular capitals and its income generating potential for society. Consequently the paper proposes a design for the value added statement that covers the majority of the six capitals (i.e. financial, human, social, relational, manufactured and intellectual capital) that management should consider according to IIRC's Framework.

However, Haller and Van Staden (2014) do not advocate just a restructured income statement to be included in integrated disclosure. Rather, they advocate the concept of value added not only to underpin corporate reporting, but also as a management accounting tool. They argue that considering value generated by the entity and the value distributed to society, will contribute to the usefulness of integrated reporting.

The above summaries of five papers in this special issue of $A A A J$ provide an indication of the contribution that the insights in these academic studies can made to developing thinking, policy and practice around integrated reporting. However, as insightful as these papers are, there are still several areas of integrated reporting that warrant further academic investigation. Indeed, because of its rapid development, integrated reporting will provide unique opportunities to examine several aspects of the regulatory process. In the next section, we discuss some of these unanswered questions and research opportunities.

\section{A research agenda to address unanswered integrated reporting questions}

The way integrated reporting is now conceptualised in 2014, with a strategic focus on future actions and plans focusing specifically value creation, stands in stark contrast with the original 2010 foci on stakeholders (other than shareholders) and accountability for the impacts of corporate activities. This shift means that the target audience for the integrated reporting is now substantively different from that of sustainability reports. While sustainability reporting aims at providing social, environmental and economic information to a wide range of stakeholders, integrated reporting now seeks to present information related to broad risk evaluation and potential future value growth thus appealing to capital providers and potential investors.

Therefore, whereas the GRI (2013) G4 guidelines emphasise the need to identify stakeholders and through their concerns to identify organisations' social and environmental impacts, the IIRC's integrated reporting framework (2013d) focus is on "shareholder value". This contrast naturally leads to several questions that would benefit from in-depth impartial academic study, especially in research about the IIRC's version of integrated reporting:

- Who will assist organisations in identifying concerns related to the social and environmental capitals (according to the IIRC, human, social and relationship, and natural capitals), if not the stakeholders who represent these capitals?

- Given this different method of identifying concerns, how will the disclosures around social and environmental (or human, social and relationship, and natural) capitals differ between (IIRC-type) integrated reports and (GRI-type) sustainability reports?

- Will the IIRC-induced systematic assessment of value creating opportunities within the realms of the social and environmental (or human, social and relationship, and natural) capitals lead to new forms of exploitation? Or

- Will more CEOs and CFOs, some for the first time, consider the direct and indirect negative influences their operations have on social and environmental (or human, social and relationship, and natural) capitals? 
- Whether senior executives endeavour to exploit social and environmental capitals or to ameliorate their influences, how will they go about balancing and weighing up the value creating and value destroying consequences of their proposed strategies?

- To what extent will specific mechanisms be created for the purpose of weighing up these matters, or will the IIRC's privileging of shareholder interests entrench the neglect of social and environmental capitals, being for the most part externalities to the organisation?

The possible broadening of the internal processes mentioned above will potentially influence risk management and audit. The concept of materiality is central to both risk and audit. In addition, the future orientation of the IIRC's integrated report implies serious consequences for firm risk and external auditors. Again, several questions are yet to be answered and represent fertile ground for future academic research:

- How will organisations, especially business organisations, deal with the risk inherent in making predictions about the future, as required by IIRC-type integrated reporting?

- How will the differences in institutional rules and structures, as well as corporate culture, in different countries influence the practice of integrated reporting, with special reference to the differential risk of litigation?

- How and to what extent will integrated reporting affect the risk of litigation of reporting organisations?

- Will integrated reporting prompt auditors to find innovative ways to deal with the issue of being unable/unwilling to express an opinion on future-oriented information?

- How and to what extent will integrated reporting affect the risk of litigation against auditors?

- How will the renewed focus on risk prompted by integrated reporting change firms' internal risk assessment processes?

- How will auditors' requirements around auditability influence internal processes, information gathering and the provision of evidence in support of increasingly future oriented disclosure?

Another implication related to the implementation of integrated reporting relates to the need to incorporate compliance methodologies into performance and assurance frameworks (KPMG, 2009). Assurance service providers may have to combine integrated reporting with existing regulatory requirements on annual reports. However, there may also be a need for regulatory bodies to change their auditing standards. This will represent another fascinating area for research, aimed at answering questions like:

- What mechanisms are most effective in prompting assurance service standard setters to change their standards to accommodate the requirements of integrated reporting?

- Will financial audit standards and sustainability assurance standards converge, and what would prompt such convergence? 
- How do standard setters deal with changed regulatory environments prompted by development of integrated reporting and how do they go about maintaining their own legitimacy and the legitimacy of their standards?

- What role do power relationships among stakeholders play in integrated reporting audit and assurance standard setting?

- Which stakeholders are most influential in affecting the direction of integrated reporting audit and assurance standard setting?

Of course, these musings on audit and assurance standard setting lead to questions around integrated reporting standard setting, such as:

- What role do power relationships among stakeholders play in integrated reporting standard setting?

- Which stakeholders are most influential in affecting the direction of integrated reporting standard setting?

- How did the IIRC establish international legitimacy so quickly, compared to, for example, the International Accounting Standards Board?

- Will there be attempts at convergence between bodies promoting integrated reporting and bodies promoting financial reporting standards such as the IIRC and the International Accounting Standards Board?

- What is the role of accountants and professional accounting bodies in creating new standards and ensuring additional work for and job reservation for members of their organisations in the context of development of integrated reporting?

- Given accountants' success at internationalising their rules and now innovating with new regulatory regimes, like integrated reporting, what and how can the other professions learn from the accounting profession?

Also, we are interested in the following additional researchable questions:

- How and to what extent are integrated reporting processes truly integrated and are these processes truly embedded in organisations' management control systems?

- How and to what extent does integrated reporting influence the short-term, medium-term, and/or longer-term perspective of: information; disclosure; and/or management orientation?

- How and to what extent does integrated reporting influence the consideration of the material impacts of the business across the entire value chain?

- How do organisations go about producing a concise integrated report, whilst covering all the capitals and all the perspectives suggested by the IIRC?

- Given that an IIRC integrated report has a particular focus, how/where is it generally published by organisations and what is its relationship to the statutory annual report?

- Is the decision to disclose an integrated report value relevant, in other words do the financial markets react or reflect a value premium in any way? 
- How can a good integrated report be distinguished from others, in other words are there particular metrics that capture the characteristics of a good integrated report? Which metrics best align with market reactions or market reflections of value?

- What can we learn from firms' integrated reports about the implementation of the IIRC guidelines and the relative importance firms ascribe to conflicting requirements?

The extent of the above questions further indicates the need for quality researchers to address a number of pressing challenges posed by the rapid development of integrated reporting policies and practices.

\section{Conclusion}

The aim of this paper is to provide academics researching in the area of integrated reporting with a solid foundation upon which to build their research and to provide regulators and reporting organisations with insights to help inform further development of policy and practice. It has addressed this aim by tracing the antecedents to early developments of and current state-of-play of integrated reporting, including explaining the key insights from other papers in this special issue of $A A A J$. It also sets out a comprehensive and challenging agenda for future research.

We believe that collectively the accounting academic community, along with other academic disciplines, has the capacity to rise to the challenge of this extensive research agenda. In so doing, it is important that research is based on solid foundations, including an appreciation and thorough grounding in the quality research that has provided robust insights into the antecedents of integrated reporting. It might be considered regrettable that some (but by no means all) of the early research around integrated reporting seemed unaware of research produced over several decades into a range social and environmental reporting practices that could have been foundations for effective stakeholder-inclusive integrated reporting. To avoid reinventing wheels and to enable researchers to focus on producing novel robust insights, we encourage researchers aiming to produce quality research in the area of integrated reporting to ensure they have a thorough grounding in the social and environmental accounting and accountability research literature, as well as the financial reporting literature.

Addressing the research questions we set out in this paper, along with others that will emerge as further research is undertaken, and as integrated reporting policy and practice develops, the academic community has an important role to play in providing a robust and impartial evidence base upon which more policies and practices can be built. This provides considerable opportunities and challenges for the academic community, but we are confident that these challenges can be met. It also provides challenges and opportunities for policy-makers and practitioners as they may have to face novel unexpected, uncomfortable and inconvenient facts and reactions related to integrated reporting. But taking these facts into account in developing policy and practice should result in stronger and more effective integrated reporting.

\section{Notes}

1. The official name of King III is: The King Code of Governance Principles for South Africa 2009.

2. On 12 March 2014, the South African Integrated Reporting Committee endorsed the International Integrated Reporting Framework, issued in December 2013, and thus committed to the emphasis on "shareholder value", available at: www.sustainabilitysa.org/Integrated Reporting/TheIntegratedReportingCommitteeofSouthAfrica.aspx (accessed 30 May 2014). 


\section{References}

ACCA (2011), "Adoption of integrated reporting by the ASX 50", available "Ad: at: accaglobal.com/pubs/general/activitiesx/library/sustainability/repor ing_pubs/tech-tp-air2.pdf (accessed 30 April 2014).

ACCA (2012), "Integrated reporting: the influence of King III on social, ethical and environmental reporting", available at: www.accaglobal.com/content/dam/acca/global/PDF-technical/ integrated-reporting/tech-tp-iirsa.pdf (accessed 22 February 2014).

ACCA and NBA (2013), "Capitals Background paper for $\langle I R\rangle$, International Integrated Reporting Council", available at: www.theiirc.org/wp-content/uploads/2013/03/IR-' BackgroundPaper-Capitals.pdf (accessed 13 May 2014).

Adams, C., Frost, G. and Webber, W. (2004), "Triple bottom line: a review of the literature", in Henriques, A. and Richardson, J. (Eds), The Triple Bottom Line, Does it All add Up? Assessing the Sustainability of Business and CSR, Earthscan, London, pp. 17-25.

Adams, S. and Simnett, R. (2011), "Integrated reporting: an opportunity for Australia's not-for-profit sector", Australian Accounting Review, Vol. 21 No. 3, pp. 292-301.

ASRC and SAC (2013), International Integrated Reporting /IRS Framework Will Bring Tremendous Benefit to Stakeholders of Firms and Attract More Firms to the Region, SAC, Singapore, available at: www.sac.gov.sg/content/dam/sac/PDFs/16Dec_International- Integrated-Reporting-Framework-will-bringtremendous-benefit-to-stakeholders-of-firms.pdf (accessed 23 February 2014).

Boltanski, L., and Thevenot, L. (1999), "The sociology of critical capacity", European Journal of Social Theory, Vol. 2 No. 3, pp. 359-377.

Boltanski, L. and Thevenot, L. (2006), On Justification: Economies of Worth, Princeton University Press, Princeton.

Brown, D., Dillard, J. and Marshall, S. (2009), "Triple bottom line: a business metaphor for a social construct", in Dillard, J., Dujon, V. and King, M.C. (Eds), Understanding the Social Dimension of Sustainability, Routledge, London, pp. 211-232.

Brown, J. and Dillard, J. (2014), "Integrated reporting: On the need for broadening out and opening up", Accounting, Auditing \& Accountability Journal, Vol. 27 No. 7, pp. 1120-1156.

Buhr, N. (2007), "Histories of and rationales for sustainability reporting", in Unerman, J., Bebbington, J. and O'Dwyer, B. (Eds), Sustainability Accounting and Accountability, Routledge, London, pp. 57-69.

Buhr, N., Gray, R. and Milne, M.J. (2014), "Histories, rationales, voluntary standards and future prospects for sustainability reporting: CSR, GRI, IIRC and beyond", in Bebbington, J., Unerman, J. and O'Dwyer, B. (Eds), Sustainability Accounting and Accountability, 2nd ed., Routledge, London, pp. 51-71.

Cheng, M., Green, W., Conradie, P., Konishi, N. and Romi, A. (2014), The international integrated reporting framework: key issues and 
future research opportunities", Journal of International Financial Management \& Accounting, Vol. 25 No. 1, pp. 90-119.

Cho, C.H., Phillips, J.R., Hageman, A.M. and Patten, D.M. (2009), "Media richness, user trust, and perceptions of corporate social responsibility: an experimental investigation of visual web site disclosures", Accounting, Auditing \& Accountability Journal, Vol. 22 No. 6, pp. 933-952.

CIMA, IFAC and PWC (2013), Business Model Background Paper for IIRS, International Integrated Reporting Council, available at: www.theiirc.org/wp-content/uploads/2013703/ Business_Model.pdf (accessed 4 June 2014).

Crane, A., Palazzo, G., Spence, L.J. and Matten, D. (2014), "Contesting the value of "creating shared value" ", California Management Review, Vol. 56 No. 2, pp. 130-153.

de Villiers, C. and van Staden, C.J. (2006), "Can less environmental disclosure have a legitimising effect? Evidence from Africa", Accounting, Organizations and Society, Vol. 31 No. 8, pp. 763781.

de Villiers, C. and van Staden, C.J. (2010), "Shareholders' requirements for corporate environmental disclosures: a cross country comparison", British Accounting Review, Vol. 42 No. 4, pp. 227240.

de Villiers, C. and van Staden, C.J. (2011), "Where firms choose to disclose voluntary environmental information", Journal of Accounting and Public Policy, Vol. 30 No. 6, pp. 504-525.

Deegan, C. (2002), "The legitimising effect of social and environmental disclosures - a theoretical foundation", Accounting, Auditing \& Accountability Journal, Vol. 15 No. 3, pp. 282-311.

Deloitte and Touche (2011), "Integrated Reporting. A better view?", available at: www.deloitte.com/ assets/DcomMiddleEast/Local\%20Assets/Documents/Services/ERS/me_ers_int egrated_reporting_sept 11.pdf (accessed 18 February 2014).

Dey, C. and Burns, J. (2010), "Integrated reporting at Novo Nordisk", in Hopwood, A., Unerman, J. and Fries, J. (Eds), Accounting for Sustainability: Practical Insights, Earthscan, London, pp. 215-232.

Eccles, R.G. and Krzus, M.P. (2010), One Report Integrated Reporting for a Sustainable Strategy, John Wiley \& Sons, New York, NY.

Elkington, J. (1998), Cannibals With Forks: The Triple Bottom Line of 21 st Century Business, New Society Publishers, Gabriola Island and Stony Creek, CT.

Elkington, J. (2004), "Enter the triple bottom line", in Henriques, A. and Richardson, J.'(Eds), The Triple Bottom Line, Does it All add Up? Assessing the Sustainability of Business and CSR, Earthscan, London, pp. 1-16.

Expert Committee on Desirable Market Economy System (2013), The report by the Expert Committee on Desirable Market Economy System, Expert Committee on Desirable Market Economy System, available at: www5.cao.go.jp/keizai-shimon/kaigi/special/market/ report.pdf (accessed 4 June 2014).

EY (2013a), EY's Excellence in Integrated Reporting Awards 2013. A 
Survey of Integrated Reports from South Africa's top 100 JSE Listed Companies and Top 10 State Owned Companies, EY, available www.ey.com/Publication/vwLUAssets/EYs Excellence in

Integrated_Reporting_Awards_2013/\$FILE/EY\%20Excēllence\%2 0in\%20Integrated\% 20 Reporting.pdf (accessed 28 April 2014).

EY (2013b), Integrated Reporting. Communicating Sustainable Value Creation, EY, London, available at: www.ey.com/Publication/vwLUAssets/Integrated_reporting Communicating sustainable value creation/\$FILE/EYIntegrated-Reporting.pdf (accessed 23 February 2014).

Fries, J., McCulloch, K. and Webster, W. (2010), "The prince's accounting for sustainability project: creating 21 st-century decision making and reporting system to respond to 21 st- century challenges and opportunities", in Hopwood, A.G., Unerman, J. and Fries, J. (Eds), Accounting for Sustainability. Practical Insights, Earthscan, London, pp. 29-46.

Frost, G., Jones, S. and Lee, P. (2012), The Collection, Integration and Reporting of Sustainability Information Within an Organisation, CPA Australia, Southbank, available at: www. cpaaustralia.com.auB/media/Corporate/AllFiles/Document/professi onal-resources/ sustainability/collection-integration-reportingsustainability.pdf (accessed 7 June 2014).

Giovannoni, E. and Maraghini, M.P. (2013), "The challenges of integrated performance measurement systems: integrating mechanisms for integrated measures", Accounting Auditing \& Accountability Journal, Vol. 26 No. 6, pp. 978-1008.

Gonzalbez, J.M. and Rodriguez, M.M. (2012), "XBRL and integrated reporting: the Spanish accounting association taxonomy approach", The International Journal of Digital Accounting Research, Vol. 12 No. 6, pp. 59-91.

GRI (2013), G4 Sustainability Reporting Guidelines, GRI, Amsterdam, available www.globalreporting.org/reporting/g4/Pages/default.aspx (accessed 12 August 2013).

Guthrie, J. and Parker, L.D. (1989), "Corporate social reporting: a rebuttal of legitimacy theory", Accounting \& Business Research, Vol. 19 No. 76, pp. 343-352.

Haller, A. and van Staden, C. (2014), "The value added statement - an appropriate instrument for Integrated Reporting", Accounting, Auditing \& Accountability Journal, Vol. 27 No. 7, pp. 1190-1216.

Higgins, C., Stubbs, W. and Love, T. (2014), "Walking the talk(s): Organisational narratives of integrated reporting", Accounting, Auditing \& Accountability Journal, Vol. 27 No. 7, pp. 1090-1119.

Hogner, R.H. (1982) "Corporate social reporting: eight decades of development at US Steel", Research in Corporate Performance and Policy, Vol. 4 No. 1, pp. 243-250.

Hopwood, A.G., Unerman, J. and Fries, J. (Eds) (2010), Accounting for Sustainability. Practical Insights, Earthscan, London.

ICAEW (2013), Integrated Reporting is a Catalyst to Improve Business Reporting Says ICAEW, ICAEW. 
IEC (2008), Preliminary Summary of Financial Accounting Standards for Environmental Liabilities, Intangible Assets and Climate Change Risk, IEC, available at: www.epa.gov/ osem/financial/edisclosure.pdf (accessed 18 February 2014).

IIRC (2011), Towards Integrated Reporting Communicating Value in the 21 st Century, IIRC, International Integrated . Reporting Committee, New York, NY, available at: http:// theiirc.org/wpcontent/uploads/2011/09/IR-Discussion-Paper-2011_spreads.pdf (accessed 14 April 2013).

IIRC. (Ed.) (2012), Prototype of the International /IRS Framework, IIRC.

IIRC (2013a), Basis for Conclusions. International /IRS Framework, IIRC, available at: www.theiirc.org/wpcontent/uploads/2013/12/13-12-08-Basis-for-conclusions-IR.pdf (accessed 21 February 2014).

IIRC (2013b), Consultation Draft of the International / IRS Framework, IIRC, International Integrated Reporting Committee, New York, NY, available at: WWw.theiirc.org/wp-content/ uploads/Consultation-Draft/Consultation-Draft-of-the-

InternationalIRFramework.pdf (accessed 14 April 2013).

IIRC (2013c), IIRC Pilot Programme Yearbook 2013. Business and Investors Explore the Sustainability Perspective of Integrated Reporting, International Integrated Reporting Council, available at: Www.theiirc.org/wp-content/uploads/2013/12/IIRC-PP-Yearbook2013_PDF4_PAGGS.pdf (accessed 5 April 2014).

IIRC (2013d), The International / IRS Framework, International Integrated Reporting Council, available at: www.theiirc.org/wpcontent/uploads/2013/12/13-12-08-THE-INTERNATIONAL- IRFRAMEWORK-2-1.pdf (accessed 23 February 2014).

IIRC (2014a), IIRC Welcomes South Africa's Endorsement of the International Integrated Reporting Framework, IIRC, available at: www.theiirc.org/2014/03/21/iirc-welcomes-south-africasendorsement-of-the-international-integrated-reporting-framework/ (accessed 13 April 2014).

IIRC (2014b), Pilot Programme Investor Network, IIRC, available at: Www.theiirc.org/companies- and-investors/pilot-programmeinvestor-network/ (accessed 1 May 2014).

IIRC and IFRS (2013), Memorandum of Understanding, IIRC and IFRS, available at: www. theiirc.org/wp-content/uploads/2013/02/MoUIIRC-IFRS-FOUNDATION-20130204.pdf (accessed 5 April 2014).

IIRC and SASB (2013), Memorandum of Understanding, IIRC and SASB, available at: www.theiirc. org/wpcontent/uploads/2014/01/MoU-IIRC-SASB-Final.pdf (accessed 5 April 2014).

Institut RSE Management (2012), The Grernlk II Act in France: A Milestone Towards Integrated Reporting, Institut RSE Management, Paris, available at: Www.institutrse.com/images/ stories/Institut_RSE The_grenelle_II_Act_in_France_June_2012.p df (accessed 4 June 2014 ).

IoDSA and King III (2009), King Code of Governance for South Africa 
2009, Institute of Directors in Southern Africa and the King Committee on Governance, available at: http: // african.ipapercms.dk/IOD/KINGIII/kingiiireport/ (accessed 23 February 2014).

IRRC (2013), Integrated Financial and Sustainability Reporting in the United States, IRRC, New York, NY, available at: http://irrcinstitute.org/pdf/FINAL_Integrated_Financial_

Sustain_Reporting_April_2013.pdf (accessed 23 February 2014).

JSIF (2013), Pension Funds and ESG Investment in Japan 2013, JSIF, Tokyo, available at: http:// media.wix.com/ugd/ebcda8_9f9f5597801b457c8aa8ce6e2fe7ecaa. pdf (accessed 4 June 2014).

Kaplan, R.S. and Norton, D.P. (1996), The Balanced Scorecard, Harvard Business School Press, Boston, MA.

KPMG (2009), Corporate Governance \& King 3, KPMG, available at: www.kpmg.com/za/en/ issuesandinsights/articlespublications/riskcompliance/pages/corporate-governance- king3.aspx (accessed 10 February 2014).

KPMG (2013), Integrated Reporting Performance Insight Through Better Business Reporting, Issue 2, KPMG, available at: www.kpmg.com/AU/en/IssuesAndInsights/Articles

Publications/Better-Business-Reporting/Documents/integratedreporting-issue-2.pdf (accessed 18 February 2014).

Laughlin, R.C. (1991), "Environmental disturbances and organizational transitions and transformations: some alternative models", Organization Studies, Vol. 12 No. 2, pp. 209-232.

Milne, M.J., Tregidga, H. and Walton, S. (2009), "Words not actions! The ideological role of sustainable development reporting", Accounting, Auditing \& Accountability Journal, Vol. 22 No. 8, pp. 1211-1257.

Mizobata, S., Bobrova, O. and Fukukawa, K. (2014), "CSR development and local community in Japan", in Fukukawa, K. (Ed.), Corporate Social Responsibility and Local Community in Asia, Routledge, London, pp. 86-97.

Neu, D., Warsame, H. and Pedwell, K. (1998), "Managing public impressions: environmental disclosures in annual reports", Accounting, Organizations and Society, Vol. 23 No. 3, pp. 265282.

Nixon, B. and Burns, J. (2012), "The paradox of strategic management accounting", Management Accounting Research, Vol. 23 No. 4, pp. 229-244.

Norreklit, H. (2003), "The balanced scorecard: what is the score? A rhetorical analysis of the balanced scorecard", Accounting, Organizations and Society, Vol. 28 No. 6, pp. 591-619.

Novo Nordisk (2013), Novo Nordisk Annual Report 2013, Novo Nordisk, available at: www. novonordisk.com/investors/annualreport-2013/default.asp (accessed 30 April 2014).

Owen, G. (2013), "Integrated reporting: a review of developments and their implications for the accounting curriculum", Accounting Education, Vol. 22 No. 4, pp. 340-356.

Parker, L.D. (2012), "Qualitative management accounting research: assessing deliverables and relevance", Critical Perspectives on Accounting, Vol. 23 No. 1, pp. 54-70.

PWC (2012), El reporting integrado en las empresas del IBEX 35. Del 
cumplimiento a la ventaja competitiva, PWC, available at: http://kc3.pwc.es/local/es/kc3/publicaciones.nsf/V1/070

88C10E04A0FDEC12579B20059844D/\$FILE/Informe\%20repotin g\%20integrado\%20 Empresas\%20IBEX_1.pdf (accessed 1 May 2014).

PWC (2013a), Communicating Performance and Prospects, PWC, available at: wWw.pwc.com/ corporatereporting (accessed 30 April 2014).

PWC (2013b), Integrated Reporting in Germany. The DAX 30 Benchmark Survey 2013, PWC, available at: www.pwc.de/de/rechnungslegung/assets/pwc-studie_integratedreporting- bei-den-dax-30-unternehmen.pdf (accessed 2 June 2014).

PWC (2013c), Integrated Reporting: Companies Struggle to Explain What Value they Create, PWC, available at: WWw.pwc.nl/nl_NL/nl/assets/documents/ir-opmars-geintegreerdeversl aggeving-stagneert.pdf (accessed 30 April 2014).

PWC (2013d), Integrated Reporting. Going Beyond the Financial Results, PWC, available

at: WWW.pwc.com/en_US/us/cfodirect/assets/pdf/point-of-viewintegrated-reporting.pdf (accessed 19 February 2014).

PWC (2013e), Momento para la diferenciacion. Las empresas del IBEX 35 avanzan hacia el reporting integrado, PWC, available at: www.pwc.es/es_ES/es/publicaciones/auditoria/ assets/reportingintegrado-ibex-35.pdf (accessed 1 May 2014).

PWC (2013f), SA's Directors Need To Get To The Value of Integrated Thinking and Reporting, PWC, available at: www.pwc.co.za/en/press-room/integrate-report.jhtml (accessed 4 June 2014).

PWC (2013g), Showing the Way Forward, PWC, available at: www.pwc.co.uk/en_uk/uk/assets/ pdf/bpta-2013-post-awardsbrochure.pdf (accessed 30 April 2014).

PWC (2014), IBEX 35 Trails FTSE 350 in Integrated Reporting, PWC, available at: wWw.pwc. com/gx/en/audit-services/corporatereporting/integrated-reporting/ibex-35-trails-ftse-350- inintegrated-reporting.jhtml (accessed 30 April 2014).

Republique Francaise (2012), Decret $n^{\circ} 2012-557$ du 24 avril 2012 relatif aux obligations de transparence des entreprises en matiere sociale et environnementale, Republique Francaise, in Francaise, R. (Ed.), available at: www.legifrance.gouv.fr/

SEC (2008), Final Rule of the Securities and Exchange Commission, SEC, available at: wWw.sec. gov/rules/final/2012/34-67716.pdf (accessed 18 February 2014).

Stubbs, W. and Higgins, C. (2014), "Integrated Reporting and internal mechanisms of change", Accounting, Auditing \& Accountability Journal, Vol. 27 No. 7, pp. 1068-1089.

The Ministry of Economy Trade and Industry of Japan (2013), Progress Report on the Corporate Reporting Lab, The Ministry of Economy Trade and Industry of Japan, available at: WWW.meti.go.jp/english/press/2013/0823_01.html (accessed 4 June 2014).

Unerman, J. (2000), "Reflections on quantification in corporate social reporting content analysis", Accounting, Auditing \& Accountability Journal, Vol. 13 No. 5, pp. 667-680. 
van Bommel, K. (2014), "Towards a legitimate compromise?: an exploration of Integrated Reporting in the Netherlands", Accounting, Auditing \& Accountability Journal, Vol. 27 No. 7, pp. $1157-1189$.

Yamagami, T. and Kokubu, K. (1991), "A note on corporate social disclosure in Japan", Accounting, Auditing \& Accountability Journal Vol. 4 No. 4, pp. 32-39.

Yonekura, A., Gallhofer, S. and Haslam, J. (2012), "Accounting disclosure, corporate governance and the battle for markets: the case of trade negotiations between Japan and the US", Critical Perspectives on Accounting, Vol. 23 Nos 4-5, pp. 312-331.

Further reading

Hoque, Z. (2014), "20 years of studies on the balanced scorecard: trends, accomplishments, gaps and opportunities for future research", The British Accounting Review, Vol. 46 No. 1, pp. 3359.

Kaplan, R.S. and Norton, D.P. (2001), "The strategy-focused organization", Strategy \& Leadership, Vol. 29 No. 3.

Norreklit, H. (2000), "The balance on the balanced scorecard a critical analysis of some of its assumptions", Management Accounting Research, Vol. 11 No. 1, pp. 65-88.

Parker, L.D. (1979), "Divisional performance measurement: beyond an exclusive profit test", Accounting and Business Research, Vol. 9 No. 36, pp. 309-319.

Corresponding author

Dr Leonardo Rinaldi can be contacted at: leonardo.rinaldi@rhul.ac.uk 